\title{
TENDÊNCIA DO NÚMERO DE DIAS DE CHUVA NO ESTADO DE GOIÁS E A RELAÇÃO DOS SEUS EXTREMOS COM O ÍNDICE OCEÂNICO NIÑO
}

\author{
TREND IN THE NUMBER OF DAYS WITH RAIN IN THE STATE OF GOIÁS \\ AND ITS RELATIONSHIP WITH EXTREME OCEAN NIÑO INDEX
}

\author{
EVOLUCION DEL NÚMERO DE DÍAS DE LLUVIA EN EL ESTADO DE GOIÁS \\ Y SU RELACIÓN CON EXTREMA DEL ÍNDICE NIÑO
}

\author{
Vanessa Romero - Instituto Federal de Goiás - Goiânia - Goiás - Brasil \\ vromero.fe@gmail.com \\ Francisco Fernando Noronha Marcuzzo - Companhia de Pesquisa de Recursos Minerais/Serviço \\ Geológico do Brasil - Porto Alegre - Rio Grande do Sul - Brasil \\ francisco.marcuzzo@cprm.gov.br \\ Murilo Raphael Dias Cardoso - DBO Engenharia - Goiânia - Goiás - Brasil \\ murilo.cardoso@me.com
}

\begin{abstract}
Resumo
Os parâmetros determinantes da precipitação pluviométrica, como o Número de Dias de Chuva (NDC), são de grande importância em estudos geográficos e ambientais, visando um melhor entendimento do clima de uma região. Com o objetivo de analisar o NDC mensal e anual no estado de Goiás, realizou-se um estudo de sua tendência ao longo do tempo e a possível correlação de seus extremos com o fenômeno El Niño Oscilação Sul quando a intensidade deste é moderada ou forte. Foram utilizadas médias mensais e anuais do NDC das séries históricas de dados pluviométricos obtidos da Rede Hidrometeorológica Nacional, da Agência Nacional de Águas e do Serviço Geológico do Brasil. Para o tratamento estatístico calcularam-se as médias temporais do número de dias com precipitação de 88 estações pluviométricas com 30 anos de dados e 26 estações com dados de 20 a 29 anos distribuídas no estado de Goiás. Como resultado final, para o período de 30 anos de dados estudados, verificou-se que houve uma tendência de diminuição média do NDC anual em Goiás de -6,1\%.
\end{abstract}

Palavras-chave: NDC, La Niña, El Niño, ENOS, precipitação pluviométrica.

\section{Abstract}

The parameters determining the rainfall, as the Number of Days of Rain (NDR), are of great importance in geographical and environmental studies, seeking a better understanding of the climate of a region. In order to analyze the NDR monthly and yearly in the state of Goiás, performed a study of its trend over time and its possible correlation with the extreme El Niño Southern Oscillation when this is with moderate or heavy. We used monthly and annual averages of the NDR of the time series of rainfall data obtained from the National Hydrometeorological Network, the National Water Agency of Brazil and the Geological Survey of Brazil. The final result for the period of 30 years of data studied, we found that there was a trend of decreasing NDC annual average of $-6.1 \%$ in Goiás.

Key words: NDR, La Niña, El Niño, ENSO, rainfall.

\section{Resumen}

Los parámetros que determinan la lluvia, como el Número de Días de Lluvia (NDL), son de gran importancia en los estudios geográficos y ambientales, en busca de una mejor comprensión del clima de una región. Con el fin de analizar la tendencia de NDLmensual y anual e nel estado de Goiás, realizó un estudio de su evolución 
en el tiempo y suposible correlación con la extrema oscilación meridional de El Niño, es cuando la intensidade es moderada o fuerte. Hemos utilizado los promedios mensuales y anuales de la NDL de la serie temporal de datos de precipitación obtenidos de la Red Nacional de Hidrometeorología, la Agencia Nacional del Agua y el Servicio Geológico de Brasil. La estadística calcula el tiempo medio el número de días con precipitaciones de 88 estaciones pluviométricas con 30 años de datos y los datos de 26 estaciones con 20 a 29 años distribuidos en el estado de Goiás. El resultado final para el período de 30 años de datos estudiados, se encontró que había una tendencia a la disminución promedio anual de NDL -6,1\% en Goiás.

Palabras clave: NDL, La Niña, El Niño, ENOS, lluvias.

Introdução

O excesso ou a ausência de chuva afeta o desenvolvimento da economia do estado de Goiás, desfavorecendo a agricultura, a pecuária, a geração de energia elétrica e o abastecimento de água urbano. Desta forma, a análise das precipitações pluviométricas e de seus condicionantes, como o Número de Dias de Chuva (NDC), é de suma importância para um melhor entendimento climático e ambiental do estado.

A caracterização da precipitação pluviométrica no Brasil tem como maior dificuldade a pouca disponibilidade de dados, ou a sua inexistência em algumas áreas do país (Mello et al., 2001).

A região Centro-Oeste não apresenta efeitos evidentes de mudanças no padrão das chuvas, em razão dos fenômenos ENOS. Todavia, há uma tendência de aumento de chuvas no sul de Mato Grosso do Sul durante as manifestações do El Niño, e previsão de que caiam muito próximas à normal climatológica registrada para os estados de Goiás, Mato Grosso do Sul e Goiás nos eventos de La Niña. Soares et al. (2008) e Marcuzzo et al. (2012b) observaram uma tendência de diminuição nos índices pluviométricos médios para a região Centro-Oeste e no estado do Tocantins, na ordem de $-6,5 \%$. Os mesmos autores concluíram que apenas os meses de março e abril apresentaram crescimento da precipitação pluviométrica.

Costa et al. (2012), em estudo sobre a espacialização e a sazonalidade da precipitação pluviométrica do estado de Goiás e no Distrito Federal, observaram que o ano mais chuvoso para a média histórica de 1974 a 2008 foi em 1983, com 1.932,8 mm, e a menor média histórica, nos 35 anos estudados, de 1.162,2 mm, no ano de 1990. Os mesmos autores detectaram que a maior variação de precipitação anual para a soma total ocorreu do ano de 1983 (1.932,8 $\mathrm{mm}$ ) para o ano de 1984 (1.258,6 $\mathrm{mm})$, acarretando uma variação negativa de precipitação da ordem de $-34,8 \%$. Verificaram também que, com 35 anos de dados, a média histórica de precipitação, 
para as 107 estações pluviométricas estudadas e distribuídas no estado de Goiás e no Distrito Federal, foi de 1.529 mm.

Na análise da tendência da chuva no estado de Goiás, Marcuzzo et al. (2012a) notaram que, em média para o estado, a maior precipitação foi de 481,9 mm no mês de dezembro, e a menor, de zero milímetro nos meses de julho e agosto. Os autores notaram que os meses que sofreram decréscimos na precipitação pluviométrica em Goiás foram janeiro, abril, maio, junho, julho, agosto, setembro, outubro, novembro e dezembro, havendo crescimento em fevereiro e março.

Para o Nordeste, os anos de El Niño (La Niña), em geral, estão associados com escassez (chuvas mais abundantes), enquanto condições contrárias são observadas no Sul e no Sudeste. Em geral, essas condições também estão relacionadas com as ocorrências de dipolos de TSM no Atlântico Tropical. Anomalias positivas (negativas) de TSM nos setores norte (sul) dessa bacia, na maior parte das vezes, também podem ocorrer em anos de El Niño, enquanto as características contrárias são observadas em anos de La Niña (Alves; Souza; Campos, 2006).

Santos e Manzi (2011), em pesquisa sobre a relação da temperatura dos oceanos tropicais com eventos extremos de precipitação no estado do Ceará, concluíram que a anomalia positiva de TSM (Temperatura na Superfície do Mar) ao norte do equador, no Oceano Atlântico, induz que a ZCIT (Zona de Convergência Intertropical) se desloque para o norte cearense, inibindo os eventos chuvosos e aumentando o número de dias consecutivos secos sobre o norte do estado.

Em anos de ocorrência de El Niño, aproximadamente 52\% dos valores de precipitação de Mossoró (RS) estiveram abaixo da média histórica. Com relação aos anos nos quais ocorreu o fenômeno La Niña, verificou-se pluviosidade acima da média em 46\% (Pereira et al., 2010).

Diante da escassez de pesquisas sobre a tendência do NDC em Goiás, este estudo tem como objetivo principal analisar a variação e a tendência mensal e anual do NDC no estado e a possível relação dos máximos e mínimos NDC com o moderado ou forte aquecimento ou esfriamento das águas do Oceano Pacifico, observando os parâmetros que se seguem. 
Caracterização da área de estudo

O estado de Goiás localiza-se na região Centro-Oeste do Brasil (Figura 1), no Planalto Central, e possui uma área de $340.103,47 \mathrm{~km}^{2}$ (IBGE, 2010). Está delimitado pelos estados do Tocantins (norte), Bahia (nordeste), Minas Gerais (sudeste e sul), Mato Grosso do Sul (sul e sudoeste), Mato Grosso (oeste e noroeste) e pelo Distrito Federal. O uso do solo no estado de Goiás está mais concentrado em atividades pecuaristas (Figura 1).

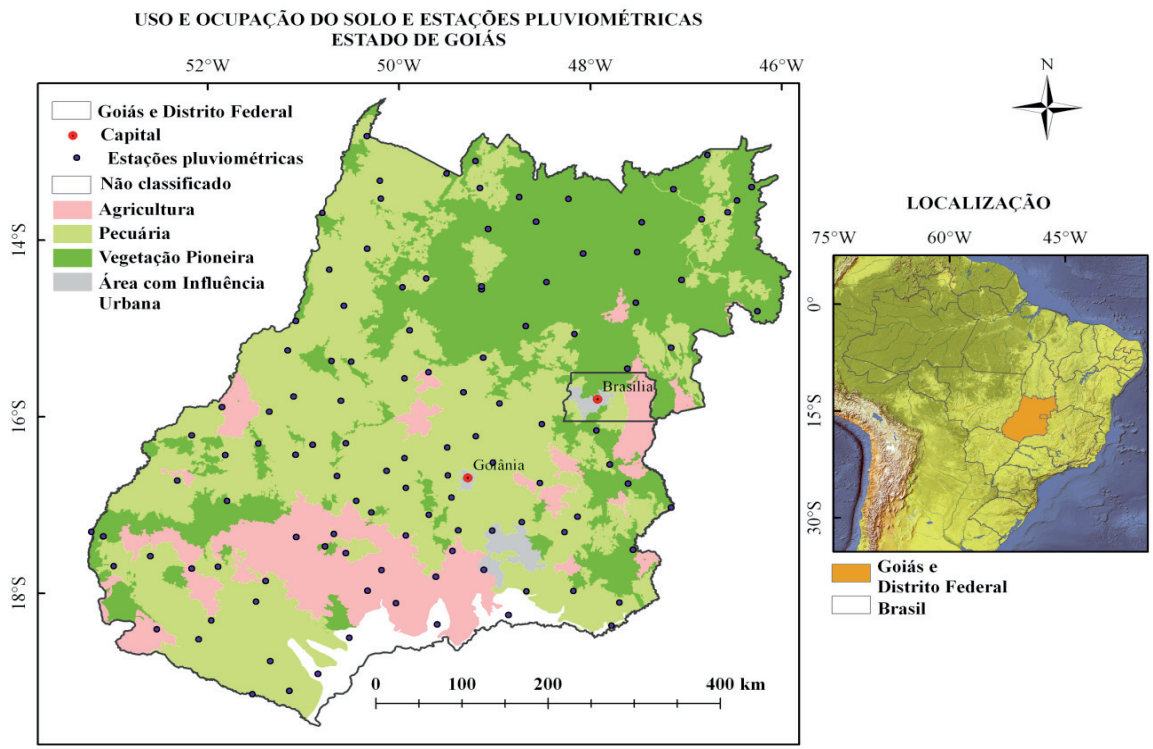

Figura 1 - Localização das estações pluviométricas e sua inserção no uso e ocupação do solo e a localização do estado de Goiás Fonte: Elaborada pelos autores, com dados do IBGE (2010) e da ANA (Brasil, 2010).

Utilizou-se neste estudo 114 estações pluviométricas (Figura 1), cujos dados diários de precipitação pluvial máxima foram obtidos na Rede Hidrometeorológica Nacional da Agência Nacional de Águas (ANA) e na Companhia de Pesquisa de Recursos Minerais / Serviço Geológico do Brasil (CPRM/SGB), que possuem 88 estações com 30 anos de dados e 26 estações com 20 a 29 anos de dados. 
Com uma população de 6.003.788 habitantes e 246 municípios, o estado de Goiás possui baixa densidade demográfica, com exceção da capital, com aproximadamente 103 hab. $\left(\mathrm{km}^{2}\right)-1$ (Figura 2). O município com menor densidade demográfica é Aporé (Figura 2), com aproximadamente 1 hab.(km²)-1 (IBGE, 2010).

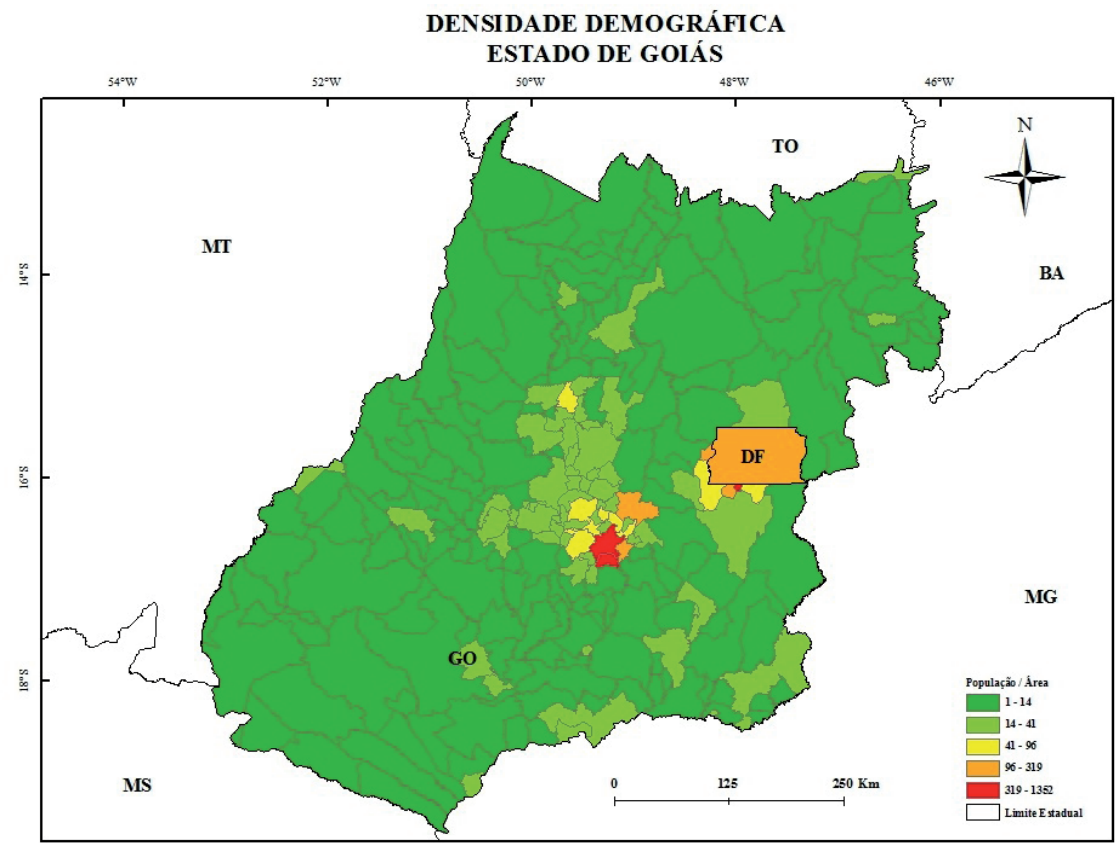

Figura 2 - Densidade demográfica do estado de Goiás

Fonte: Elaborada pelos autores, com dados do IBGE (2010).

Existem três climas atuantes no estado, segundo a classificação climática de Köppen: o tropical, com estação seca no inverno (Aw); o temperado úmido, com inverno seco e verão quente (Cwa); e o temperado úmido, com inverno seco e verão temperado (Cwb) (Figura 3). Em sua maior parte, o estado encontra-se inserido no bioma de cerrado, vegetação típica de regiões com estações climáticas bem definidas (estações seca e chuvosa). Pequena parte do estado está inserida na Mata Atlântica (Figura 3). 


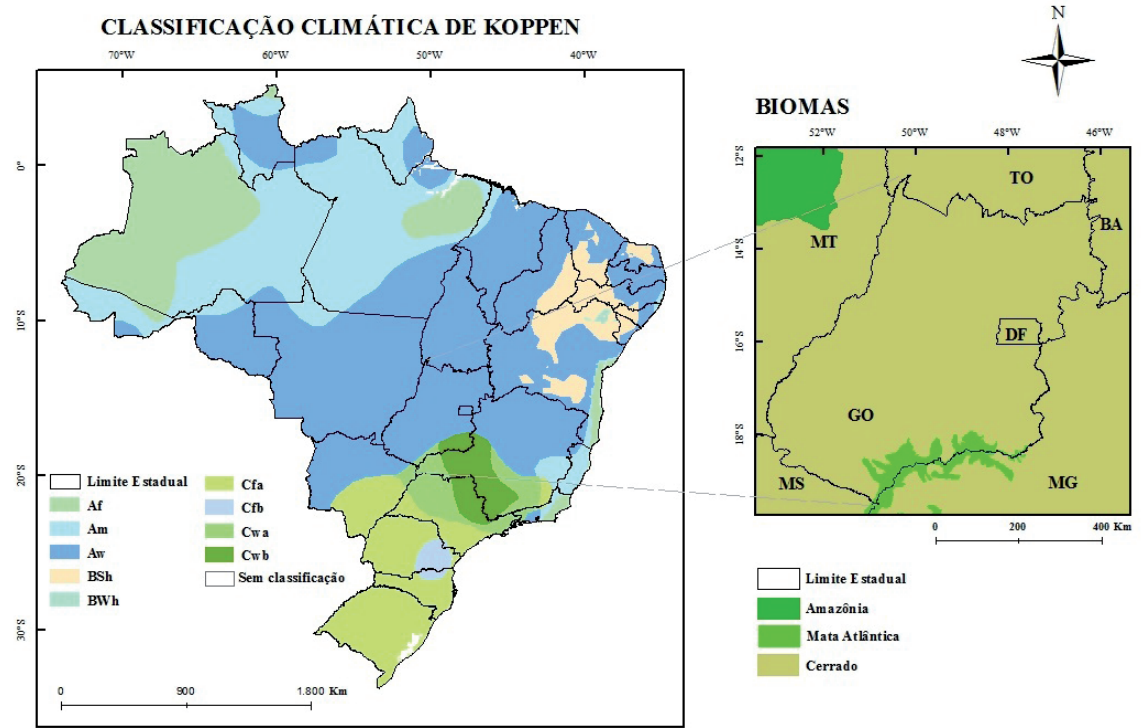

Figura 3 - Clima (classificação de Köppen) e biomas do estado de Goiás

Fonte: Elaborado pelos autores, com dados de Peel, Finlayson e Mcmahon (2007) e IBGE (2010).

Dados utilizados e metodologia

Os dados de precipitação pluvial máxima diária das 114 estações pluviométricas locadas no perímetro de abrangência do estado de Goiás foram compilados, consistidos, organizados e tratados estatisticamente, com informação diária, mensal, anual e sazonal.

O Índice de Oscilação Sul (ION), ferramenta de análise utilizada neste estudo, caracteriza-se pela diferença de pressão em regiões da Polinésia e da Austrália. É um índice que identifica as anomalias da superfície do oceano Pacífico mediante uma média móvel de três meses (Quadro 1). Quando o ION for maior que $+0,5^{\circ} \mathrm{C}$ por no mínimo cinco meses consecutivos, o período é caracterizado como El Niño, e quando o índice for menor que $-0,5^{\circ} \mathrm{C}$ por no mínimo cinco meses consecutivos, como La Niña. 
Quadro 1 - Classificação da intensidade do Índice Oceânico Niño(a)

\begin{tabular}{|c|c|c|}
\hline Evento & Índice Oceânico Niño(a) & Intensidade \\
\hline \multirow{3}{*}{ El Niño } & 0,5 a 0,9 & Fraca \\
\cline { 2 - 3 } & 1,0 a 1,4 & Moderada \\
\cline { 2 - 3 } & $\geq 1,5$ & Forte \\
\hline \multirow{3}{*}{ La Niña } & $-0,5$ a $-0,9$ & Fraca \\
\cline { 2 - 3 } & $-1,0$ a $-1,4$ & Moderada \\
\cline { 2 - 3 } & $\leq-1,5$ & Forte \\
\hline
\end{tabular}

Fonte: Adaptado de Golden Gate Weather Services (2008).

Os dados de intensidade dos fenômenos niños de 1977 a 2006 (Figura 4) foram obtidos no Serviço Climatológico Nacional dos Estados Unidos (NOAA - NationalWeather Service) e manipulados, juntamente com os dados de precipitação pluvial, durante o período de ago./2011 a jun./2012, permitindo a análise da tendência dos dias de chuva no estado de Goiás.

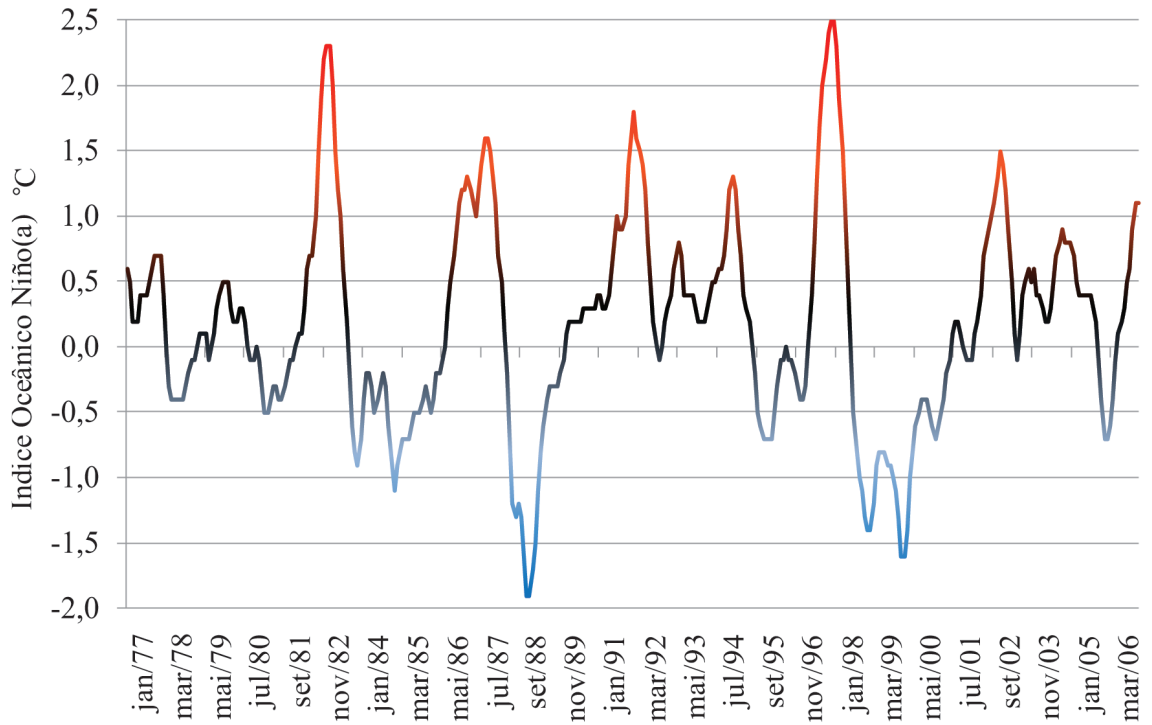

Figura 4 - Índice Oceânico Niño(a) de 1977 a 2006

Fonte: Elaborado pelos autores, com dados da NOAA (2011). 
Os valores em vermelho, azul e preto da Figura 4 correspondem, respectivamente, ao El Niño, à La Niña e aos valores considerados normais de aumento ou redução de temperatura do Oceano Pacífico.

Neste trabalho utilizaram-se dados do projeto Shuttle Radar Topology Mission (SRTM), com resolução de 90 metros. As imagens SRTM foram agrupadas no programa Geographic Information System (GIS). Posteriormente, o Modelo Digital de Elevação (MDE) foi delimitado, permitindo analisar a hipsometria do estado de Goiás, que se caracteriza por terras cujas altitudes variam de 184 a 1.670 metros, resultando num gradiente altimétrico de 1.486 metros. As terras mais altas de Goiás localizam-se na região do Distrito Federal e proximidades (Figura 5).

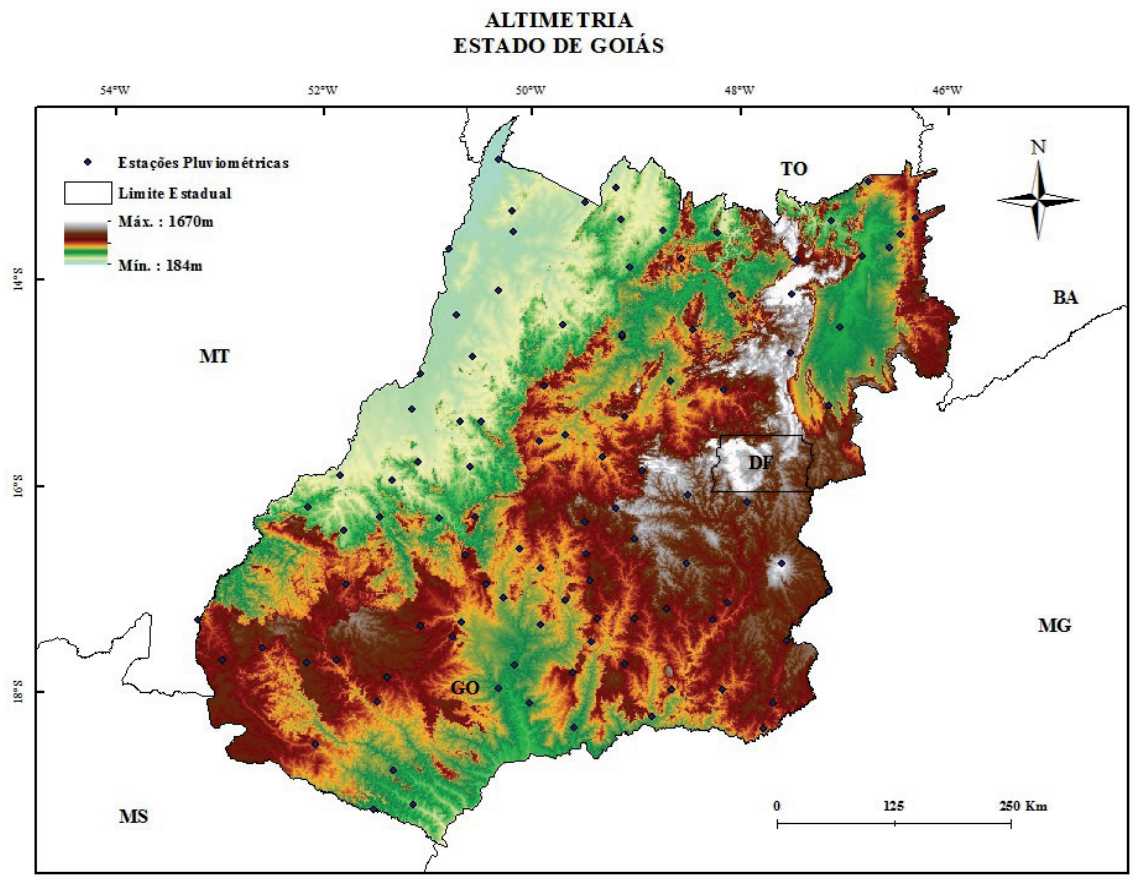

Figura 5 - Localização das estações pluviométricas na altimetria e no bioma de Goiás Fonte: Elaborado pelos autores, com dados de SRTM (Shuttle Radar Topology Mission), ANA (2010) e IBGE (2010). 
A metodologia utilizada para sistematizar os dados foi de regressão linear e polinomial, que estima um valor condicional esperado, e também a estatística descritiva, que permite calcular as medidas de tendência central e as medidas de dispersão.

Utilizando-se as medidas de tendência central e de dispersão podem-se verificar analiticamente os parâmetros e observar se as amostras são diferentes ou semelhantes.

\section{Tendência do NDC mensal em Goiás}

A distribuição dos Números de Dias de Chuvas (NDC) das médias mensais, com base nos dados da série histórica de 1977 a 2006, registradas em 114 estações pluviométricas distribuídas no estado de Goiás, apresenta uma variação significativa. O maior NDC observado, para o mês de janeiro (Figura 6a), foi de 23,7 no ano de 1985, caracterizado por um período de La Niña fraco (Quadro 1 e Figura 4). O menor foi de 11,2 no ano de 1993, totalizando uma variação do maior para o menor NDC, para a série histórica estudada, de 52,7\%. Para o período de 1977 a 2006, observou-se uma tendência média de redução do NDC de -14,5\% no mês de janeiro.

O maior NDC observado, para o mês de fevereiro (Figura 6b), foi de 19,4, no ano de 1980. O menor foi de 7,5, no ano de 1981, totalizando uma variação do maior para o menor NDC, para a série histórica estudada, de $61,3 \%$. Observou-se uma tendência média de acréscimo do NDC na ordem de $+9,1 \%$ no mês de fevereiro.

O maior NDC para o mês de março (Figura 6c) observado foi de 18,6 no ano de 1982 e 1991e o menor foi de 7,0 no ano de 1980, totalizando uma variação do maior para o menor NDC, para a série histórica estudada, de $62,4 \%$. Para o período de 1977 a 2006 observou-se uma tendência média de crescimento do NDC de 28,0\% no mês de março, sendo este e o mês de fevereiro, os únicos em que houve tendência positiva de NDC para a série histórica estudada no estado de Goiás.

O maior NDC para o mês de abril (Figura 6d), observado foi de 10,4 no ano de 2004, e o menor foi de 2,8, no ano de 2002, totalizando uma variação do maior para o menor NDC, para a série histórica estudada, de 73,1\%. Observou-se uma tendência média de redução do NDC de -17,3\% no mês de abril, para todo o estado de Goiás. 


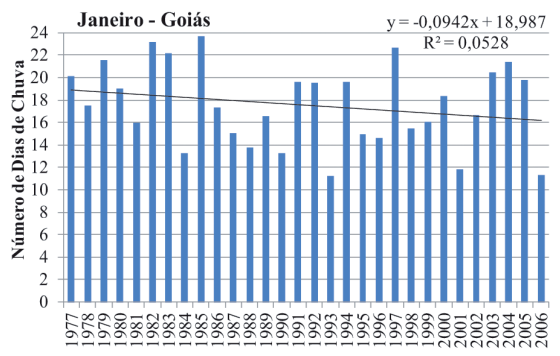

(a)

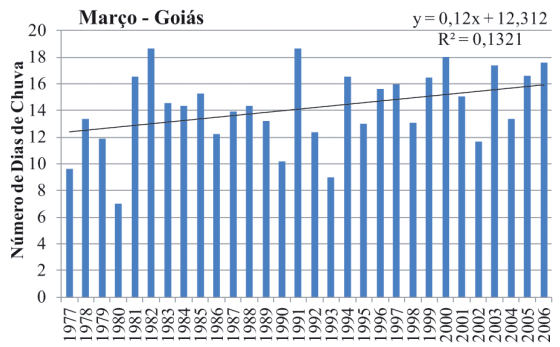

(c)

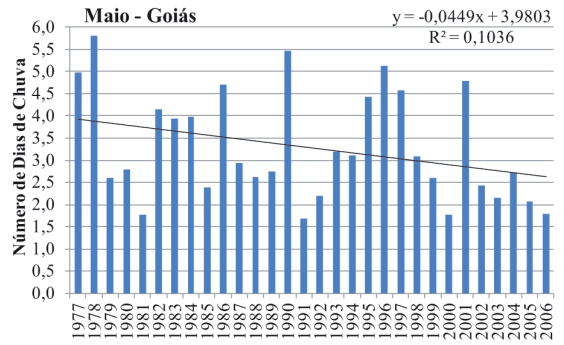

(e)

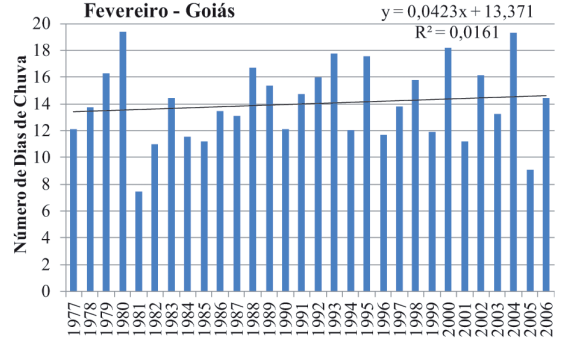

(b)

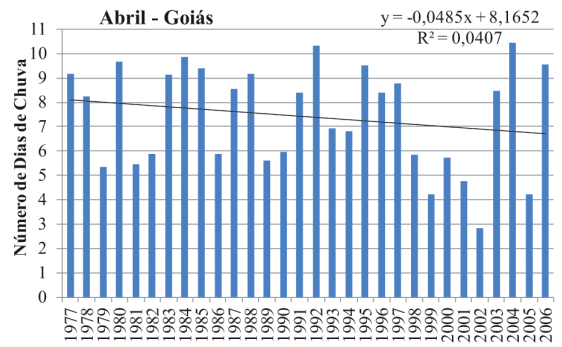

(d)

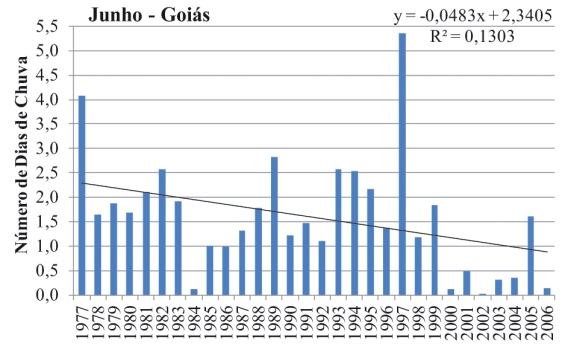

(f)

Figura 6 - Tendência de NDC nos meses de janeiro (a), fevereiro (b), março (c), abril (d), maio (e) e junho (f) em Goiás.

Fonte: Elaborada pelos autores.

No mês de maio (Figura 6e), o maior NDC observado em Goiás foi de 5,8, no ano de 1978, e o menor foi de 1,7, no ano de 1991, totalizando uma variação do maior para o menor NDC, para a série estudada, de 70,7\%. Para o mês de maio, observou-se uma tendência média de decréscimo do NDC de $-33,1 \%$. 
No mês de junho (Figura 6f), o maior NDC observado no estado foi de 5,4 no ano de 1997, início de um período de forte El Niño (Figura 4). O menor foi de zero, no ano de 2002, início de um período de aquecimento das águas do Oceano Pacífico (Figura 4), totalizando uma variação do maior para o menor NDC, para a série histórica estudada, de 100\%. Para o mês de junho, no período de 1977 a 2006, observou-se uma tendência média de decréscimo do NDC de -61,1\%.

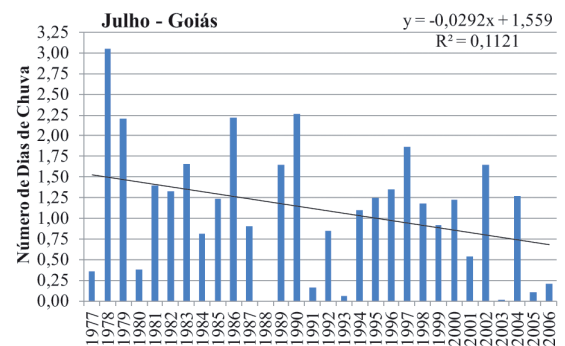

(a)

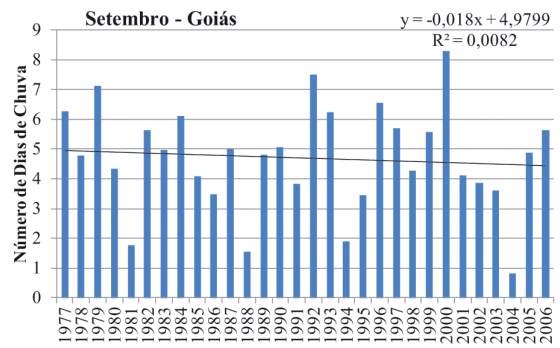

(c)

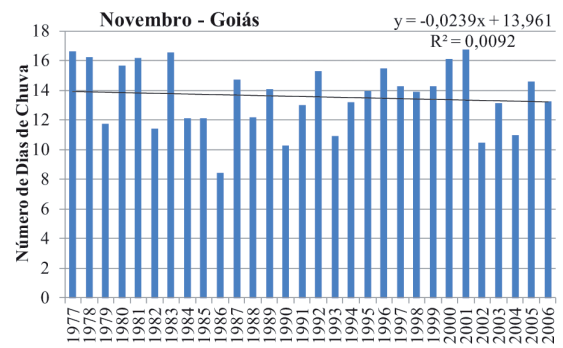

(e)

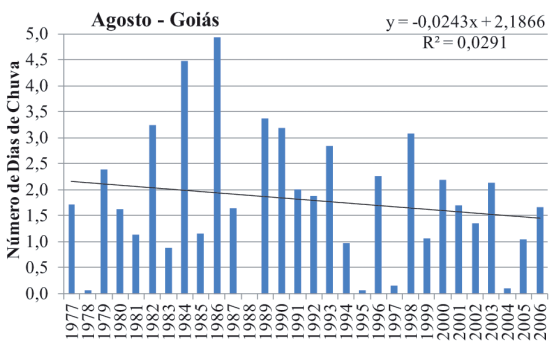

(b)

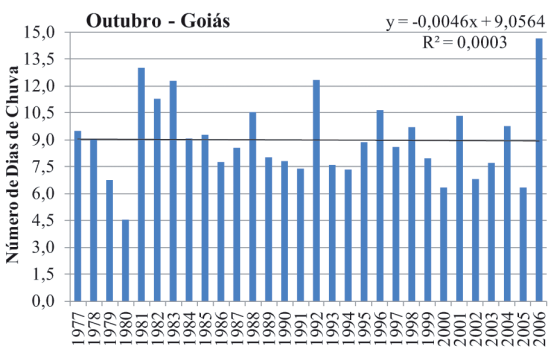

(d)

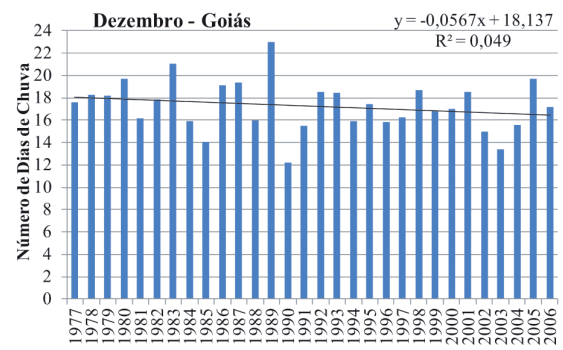

(f)

Figura 7 - Tendência de NDC nos meses de julho (a), agosto (b), setembro (c), outubro (d), novembro (e) e dezembro (f) em Goiás 
No mês de julho (Figura 7a), o maior NDC observado foi de 3,1 no ano de 1979 e o menor foi de zero nos anos de 1988, início de forte La Niña (Figura 4), e 2003, totalizando uma variação do maior para o menor NDC, para a série histórica estudada, de 100\%. Para o mês de julho, observou-se uma tendência média de decréscimo do NDC de -55,4\%.

Para o mês de agosto (Figura 7b), o maior NDC registrado em Goiás foi de 4,9 no ano de 1986, início do aquecimento das águas do Oceano Pacífico (Figura 4), e o menor foi de zero em 1988, ano de forte La Niña (Figura 4), totalizando uma variação do maior para o menor NDC, para a série histórica estudada, de $100 \%$. Para o mês de agosto, no período de 1977 a 2006, observou-se uma tendência média de decréscimo do NDC de $-32,6 \%$.

Para o mês de setembro (Figura 7c), o maior NDC observado no estado foi de 8,3 no ano de 2000, período de fraco esfriamento das águas do Oceano Pacífico, e o menor foi de 0,8 no ano de 2004, ano de fraco El Niño (Figura 4), totalizando uma variação do maior para o menor NDC, para a série histórica estudada, de 90,4\%. Para o mês de setembro, no período de 1977 a 2006, observou-se uma tendência média de decréscimo do NDC de $-10,5 \%$.

Para o mês de outubro (Figura 7d), o maior NDC observado foi de 14,7 no ano de 2006, período de fraca a moderada La Niña (Figura 4) e o menor foi de 4,6 no ano de 1980, totalizando uma variação do maior para o menor NDC, para a série histórica estudada, de 68,7\%. Para o mês de outubro, no período de 1977 a 2006, observou-se uma tendência média de decréscimo do NDC de $-1,5 \%$.

No mês de novembro (Figura 7e), o maior NDC observado foi de 16,7 no ano de 2001 e o menor foi de 8,5 no ano de 1986, totalizando uma variação do maior para o menor NDC, para a série histórica estudada, de 49,1\%. Para o mês de novembro, no período de 1977 a 2006, observou-se uma tendência média de decréscimo do NDC de -5,0\%.

Para o mês de dezembro (Figura 7f), o maior NDC observado no estado foi de 18,1 no ano de 1989, e o menor foi de 12,2 no ano de 1990, totalizando uma variação do maior para o menor NDC, para a série histórica estudada, de 47,0\%. Para o mês de dezembro, no período de 1977 a 2006, observou-se uma tendência média de decréscimo do NDC de -9,1\%. 
Tendência do NDC anual total em Goiás

O maior NDC observado no estado de Goiás para a soma histórica anual (Figura 8a) foi de 123 no ano de 1983, meio e fim de um período forte de La Niña, e o menor foi de 89 no ano de 1990, período sem El Niño ou La Niña (Figura 4). A variação do maior para o menor foi de $28 \%$. Observa-se também que as oscilações interanuais não são bruscas, e as tendências de decréscimo do NDC total anual ficam, em média, na ordem de -6,1\% de 1977 a 2006. Na Figura 8b, observa-se que na evolução decadal média, do período de 30 anos estudado, houve uma tendência média de diminuição dos dias de chuva para os meses do ano, no estado de Goiás, década após década, conforme relatado na discussão das Figuras 5 e 6, havendo poucas exceções (fevereiro e março).

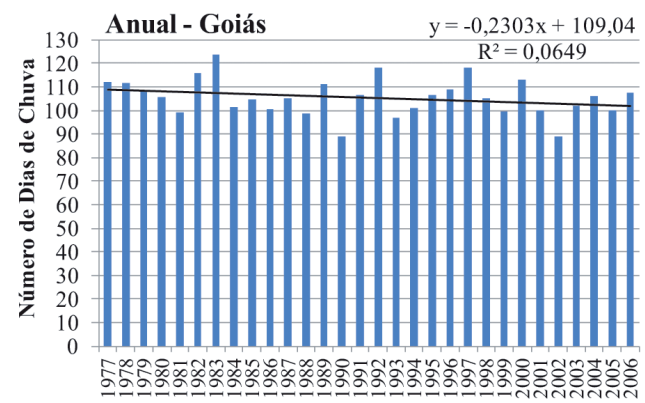

(a)

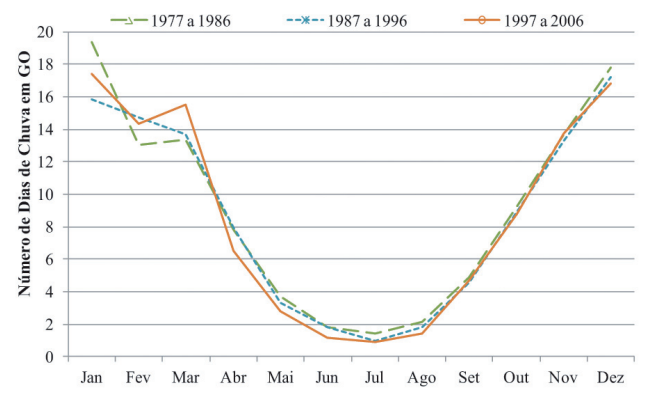

(b)

Figura 8 - Tendência de NDC interanual em Goiás (a) e a evolução do NDC da média mensal, para as três décadas estudadas (b), entre 1977 e 2006 
Distribuição mensal do NDC, com análise estatística

Na Figura 9 verifica-se a distribuição média do Número de Dias de Chuva (NDC) nos meses do ano, para o período de 1977 a 2006 no estado de Goiás. Verificam-se também as máximas, mínimas e a tendência polinomial média no decorrer dos meses do ano.

Observa-se que, em média, o mês de janeiro possui o maior NDC médio $(17,4)$ em Goiás (Figura 9 e Tabela 1), além da maior máxima $(19,4)$. A maior mínima $(12,2)$ na série histórica foi no mês de dezembro. Verifica-se que, em média, os meses de junho, julho e agosto possuem o menor NDC (zero) em Goiás e a menor média $(1,1)$ em julho. A menor máxima $(3,1)$ no ano foi observada no mês de julho.

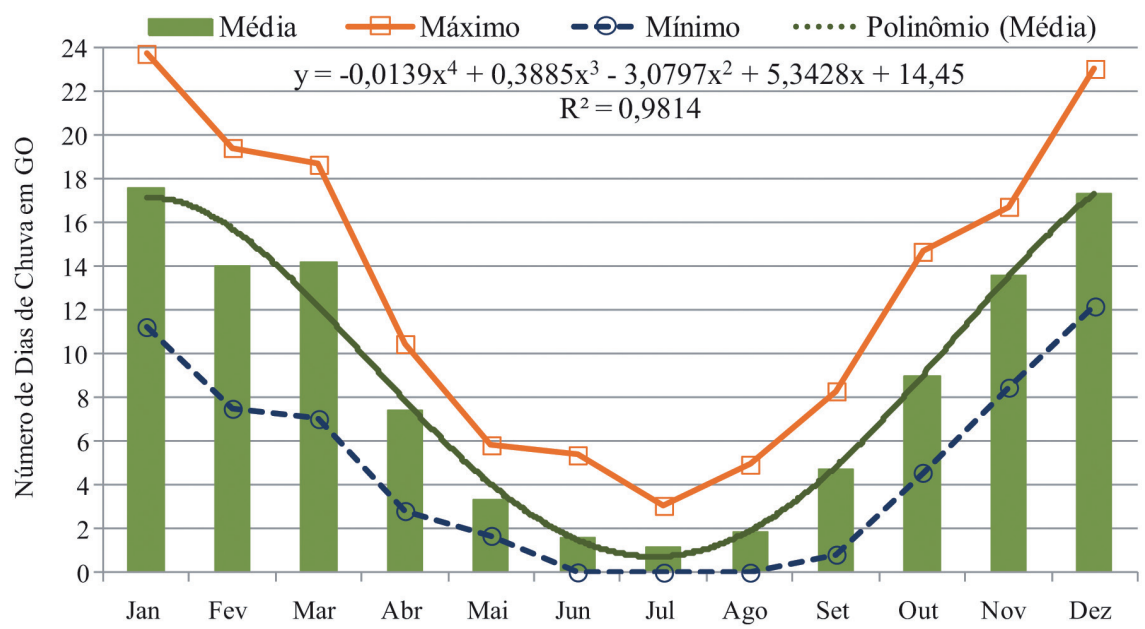

Figura 9 - Histograma de NDC da média mensal, suas máximas, mínimas e tendência polinomial em Goiás, para o período de 1977 a 2006 Fonte: Elaborada pelos autores.

Na análise estatística (Tabela 1) verifica-se que o máximo NDC do estado de Goiás foi obtido no mês de janeiro $(23,7 \mathrm{~mm})$ de 1985, quando o Índice Oceânico Niño estava em $-0,9^{\circ} \mathrm{C}$, ou seja, passando por La Niña de intensidade fraca (Figura 4). 
Tabela 1 - Análise estatística da precipitação máxima diária de Goiás (1977 a 2006)

\begin{tabular}{|c|c|c|c|c|c|}
\hline Meses & Máx. & Méd. & Med. & Mín. & Des. Padrão \\
\hline Jan & 23,7 & 17,4 & 17,4 & 11,2 & 3,6 \\
\hline Fev & 19,4 & 14,0 & 13,8 & 7,5 & 2,9 \\
\hline Mar & 18,6 & 14,2 & 14,3 & 7,0 & 2,9 \\
\hline Abr & 10,4 & 7,4 & 8,3 & 2,8 & 2,1 \\
\hline Mai & 5,8 & 3,3 & 2,9 & 1,7 & 1,2 \\
\hline Jun & 5,4 & 1,6 & 1,5 & 0,0 & 1,2 \\
\hline Jul & 3,1 & 1,1 & 1,2 & 0,0 & 0,8 \\
\hline Ago & 4,9 & 1,8 & 1,7 & 0,0 & 1,3 \\
\hline Set & 8,3 & 4,7 & 4,8 & 0,8 & 1,8 \\
\hline Out & 14,7 & 9,0 & 8,7 & 4,6 & 2,2 \\
\hline Nov & 16,7 & 13,6 & 13,9 & 8,5 & 2,2 \\
\hline Dez & 23,0 & 17,3 & 17,3 & 12,2 & 2,3 \\
\hline Anual & 123,4 & 105,5 & 105,5 & 88,8 & 8,0 \\
\hline
\end{tabular}

Fonte: Elaborada pelos autores.

A tendência central (média), que é o centro de um grupo de números em uma distribuição estatística, para os valores de NDC, mostrou uma maior proximidade com os valores máximos nos meses chuvosos (outubro a abril) em relação aos meses secos (maio a setembro) (Costa et al., 2012), que tiveram maior proximidade com os valores mínimos. Nos meses mais úmidos, verifica-se que a mediana ficou muito próxima da média e se distanciando da mesma nos meses mais secos. A medida do grau de dispersão dos valores em relação ao seu valor médio mostra que, em média, nos meses de maior NDC (meses mais chuvosos) o desvio padrão foi relativamente maior que nos meses com menores valores (meses mais secos). O maior desvio padrão foi obtido no mês de janeiro $(3,6)$, considerado o mês mais úmido do ano hidrológico para o estado (Marcuzzo et al., 2011), e o menor desvio padrão foi obtido no mês de julho $(0,8)$, considerado mês seco (Tabela 1).

\section{Considerações finais}

Entre os anos de 1977 a 2006, verificaram-se no estado de Goiás, para as 114 estações pluviométricas estudadas, um decréscimo médio anual no NDC de -6,1\%. Os meses de primavera e verão obtiveram os maiores valores médios de NDC para o período estudado, ficando os meses de outono e inverno com os menores valores. O mês de janeiro é o que 
possui maior NDC médio $(17,5)$ e o mês de julho, o menor NDC médio de Goiás $(1,1)$.

Observou-se que apenas os meses de fevereiro $(+9,1 \%)$ e março (de $+28,0 \%$ ) apresentaram tendência de aumento do NDC, para a série histórica estudada de 30 anos, ficando os outros meses e a média geral anual $(-6,1 \%)$, com tendência de decréscimo no NDC do estado de Goiás. O ENOS teve pouca influência nos valores máximos e mínimos do NDC para a série histórica estudada. Em ordem crescente de valores percentuais, os meses que apresentaram tendência de decréscimo no NDC no estado de Goiás, entre 1977 e 2006, foram: junho (-61,1\%), julho (-55,4\%), maio $(-33,1 \%)$, agosto $(-32,6 \%)$, abril $(-17,3 \%)$, janeiro $(-14,5 \%)$, setembro $(-10,5 \%)$, dezembro $(-9,1)$, novembro $(-5,0 \%)$ e outubro $(-1,5 \%)$.

\section{Agradecimentos}

Os autores agradecem à Companhia de Pesquisa de Recursos Minerais/Serviço Geológico do Brasil (CPRM/SGB), empresa pública de pesquisa do Ministério de Minas e Energia, pelo fomento que viabilizou o desenvolvimento deste trabalho.

\section{Referências}

ALVES, J. M. B.; SOUZA, R. O.; CAMPOS, J. N. B. Previsão da anomalia de Temperatura da Superfície do Mar (TSM) no Atlântico Tropical, com a equação da difusão de temperatura. Revista Climanálise, Instituto Nacional de Pesquisas Espaciais (INPE), São José dos Campos, SP, Ano 3, n. 1, p. 6-19, 2006. Disponível em: <http://www6.cptec.inpe.br/revclima/revista/pdf/artigorevTSM_0506.pdf>. Acesso em: 16 ago. 2012.

BRASIL. Agência Nacional de Águas (ANA). Hidroweb. Brasília: ANA, 2010. Disponível em: <http://www.ana.gov.br>. Acesso em: 10 dez. 2010.

COSTA, H. C.; MARCUZZO, F. F. N.; FERREIRA, O. M.; ANDRADE, L. R. Espacialização e Sazonalidade da Precipitação Pluviométrica do Estado de Goiás e Distrito Federal. Revista Brasileira de Geografia Física. Recife, v. 5, n. 1, p. 87100, 2012. Disponível em: < http://www.ufpe.br/rbgfe/index.php/revista/article/ view/291/254>. Acesso em: 14 ago. 2012.

IBGE. Instituto Brasileiro de Geografia e Estatística. Rio de Janeiro: IBGE, 2010. Disponível em: <http://www.ibge.gov.br/cidadesat/link.php?uf=to>. Acesso em: 10 out. 2011.

MARCUZZO, F. F. N.; FARIA, T. G. PINTO FILHO, R. de F. Chuvas no Estado de Goiás: análise histórica e tendência futura. Acta Geográfica, Boa Vista, v. 6, n. 
12, p. 113-125, 2012. DOI: 10.5654/actageo2012.0612.0007. Disponível em: <http:// revista.ufrr.br/index.php/actageo/search>. Acesso em: 16 ago. 2012.

; OLIVEIRA, N. de L.; PINTO FILHO, R. de F.; FARIA, T. G. Chuvas na região Centro-Oeste e no Estado do Tocantins: análise histórica e tendência futura. Boletim de Geografia, Maringá, SP, v. 30, n. 1, p. 19-30, 2012. Disponível em: <http://periodicos.uem.br/ojs/index.php/BolGeogr/article/view/13418/9371>. Acesso em: 6 ago. 2012.

MELLO, C. R.; FERREIRA, D. F.; SILVA, A. M.; LIMA, J. M. Análise de modelos matemáticos aplicados ao estudo de chuvas intensas. Revista Brasileira de Ciência do Solo. Viçosa, MG, v. 25, n. 3, 2001, p. 693-698. Disponível em: <http://sbcs. solos.ufv.br/solos/revistas/v25n3a18.pdf>. Acesso em: 3 ago. 2012.

NOAA - National Weather Service (2011). Monthly Atmospheric \& SST Indices. Disponível em: <http://www.cpc.ncep.noaa.gov/data/indices/>. Acesso em: fev. 2012.

PEEL, M. C.; FINLAYSON, B. L.; MCMAHON, T. A. Updated World Map of the Köppen-Geiger Climate Classification. Hydrology Earth System. Science, 11, p. 1633-1644, 2007. Disponível em: <http://www.hydrol-earth-syst-sci. net/11/1633/2007/hess-11-1633-2007.pdf>. Acesso em: 16 ago. 2012.

PEREIRA, V. C.; SOBRINHO, J. E.; OLIVEIRA, A. D.; VIEIRA, R. Y. M.; MELO, T. K.; MELO, S. B.; SILVA, F. G. Influência dos eventos El Niño e La Niña na precipitação pluviométrica de Mossoró-RN. In: CONGRESSO BRASILEIRO DE METEOROLOGIA, 16, 2010, Belém-PA. Anais eletrônicos. Belém: SBMET, 2010. Disponível em: <http://www.cbmet2010.com/anais/artigos/60_46462.pdf>. Acesso em: 2 jan. 2012.

SANTOS, C. A. C.; MANZI, A. O. Eventos extremos de precipitação no estado do Ceará e suas relações com a temperatura dos Oceanos Tropicais. Revista Brasileira de Meteorologia, São Paulo, v. 26, n. 1, p. 157-165. 2011. Disponível em: <http:// www.scielo.br/pdf/rbmet/v26n1/a14v26n1.pdf>. Acesso em: 16 ago. 2012.

SOARES, S. C.; MOURA, C. R. W.; COLTRI, P. P.; JÚNIOR, C. M. Efeitos do El Niño e da La Niña na Agricultura Brasileira. Instituto Nacional de Pesquisas Espaciais -INPE. 2008. Disponível em: <http://www7.cptec.inpe.br/noticias/noticia/8530>. Acesso em: 28 maio 2012.

Vanessa Romero - Tecnóloga em Saneamento Ambiental, Acadêmica em Geoprocessamento no Instituto Federal de Goiás, Departamento de Geomática.

Francisco Fernando Noronha Marcuzzo - Possui Graduação pela Universidade Estadual Paulista. Mestre em Irrigação e Drenagem pelo Departamento de Engenharia Rural da Universidade Estadual Paulista. Doutor em Engenharia Hidráulica e Saneamento pela Universidade de São Paulo. Possui Pós-doutorado em Engenharia Hidráulica e Saneamento pela Universidade de São Paulo. Atualmente é Pesquisador em Geociências na área de Engenharia Hidrológica da Companhia de Pesquisa de Recursos Minerais (CPRM), Serviço Geológico do Brasil, do Ministério de Minas e Energia. 
Murilo Raphael Dias Cardoso - Possui Graduação pela Universidade Federal de Goiás. Possui especialização em andamento em Economia e Meio Ambiente pela Universidade Federal do Paraná. Atualmente é analista em Geoprocessamento na empresa DBO Engenharia.

Recebido para publicação em 24 de agosto de 2014 Aceito para publicação em 21 de outubro de 2014 